\title{
Between Twins; Research Summaries; In the Real World
}

\author{
Nancy L. Segal \\ Department of Psychology, California State University, Fullerton, California, USA
}

\begin{abstract}
Research on unusually long birth intervals between twin and triplet deliveries is reviewed. A recent multicentre study reported Rgestational and survival data for 35 multiple birth sets from 12 centers, and evaluated conservative treatment strategies for mothers delivering one twin fetus. Next, findings from three recent twin studies are reviewed: effects of close inter-twin communication on longevity; case report of dizygous twins with a single chorion; and a case of discordance for hemihypertrophy in an $\mathrm{MZ}$ female twin pair. The article concludes with summaries of three interesting and informative anecdotal accounts of twins.
\end{abstract}

\section{Between Twins: Birth Intervals}

Three commonly asked questions of twins and their families concern (1) twin type, (2) birth order and (3) birth interval. The answer to question three is usually "minutes," especially if delivery was by cesarean section. However, there are rare cases of twins delivered days, weeks and even months apart. The first such case, in which twin deliveries were separated by 44 days, was reported by Carson (1888). This information has been considered newsworthy by the press which is usually the way I have known of such pairs. I suspect that the huge time gap between the delivery of some co-twins is of interest because we expect twins to enter the world together - so when they do not they attract attention.

Unfortunately, less concern has been given to the nature and impact of substantial birth intervals between twins. What are the causes? What are the effects? In the event that one twin is delivered prematurely, what is the best course of care for the mother still carrying the second twin? A recent multicentre study has addressed many of these issues. Before describing this work, it seems appropriate to look more closely at some of the cases.
1. "30-Day Delay in Delivery of Second Twin" (Benden et al., 2001). A 30-year-old woman presented at 23 weeks, 3 days gestation with a twin pregnancy. The twins were diamniotic and dichorionic. A female fetus was delivered at 24 weeks, 2 days in the absence of medical intervention. Following that, she received tocolysis (inhibition of uterine contractions via medication) and antibiotic therapy. A healthy male co-twin was delivered at 29 weeks.

2. "Sixty-one Day Twin to Twin Birth Interval in a Low Technology Setting" (Odukogbe et al., 2002). A 30-year-old woman, who had already delivered a set of twins, spontaneously aborted a female fetus at 25 weeks, 2 days. She was put on bed rest and medication. A healthy male co-twin was delivered 61 days later, at 33 weeks, 2 days.

3. "Boy is Born 5 Months After his Twin Died" (New York Times, 1999). A mother gave birth to a healthy male twin 152 days after delivery of his co-twin at 15 weeks. She had received drug therapy, surgical intervention and other treatment protocols to prevent labor. This twin birth interval may be "the record".
A recent multicentre study, reported by Fayad and colleagues (2003), in France, Switzerland and Belgium, examined 35 cases of delayed delivery of the second twin. The aim was to assess the effects of conservative treatment of multiple birth mothers after delivery of the first twin. Participants came from 12 out of 20 centers invited to participate. Data were gathered between April 1999 and February 2000.

The 35 cases included 28 twin pairs and 7 triplet sets. For twins, the mean birth interval was 47 days. Mean gestational age of the first twin was 20.8 weeks $(+5.5)$ and mean gestational age of the second twin was $27.9(+4.6$ weeks). Among first deliveries 7.4\% survived, and among second deliveries $78.6 \%$ survived. The triplet sets had two deliveries. (It appears that the second and third triplets were delivered together, but that is not entirely clear from the report.) The mean birth interval was 22.7 days. Among first deliveries $9.8 \%$ survived, among second deliveries 19\% survived and among third deliveries $14.2 \%$ survived. The overall survival rate for triplets was

Address for correspondence: Nancy L. Segal Department of Psychology, California State University, Fullerton, CA 92834 USA. Email: nsegal@fullerton.edu 
$42.8 \%$. Gestational ages were not reported for triplets.

Evaluating a conservative strategy for managing these cases was of interest. A conservative strategy is an alternative to ending a pregnancy, and tries to achieve a minimal viable age for delivery of the second twin. It consists of strict bed rest, continuous or periodic hospitalization, high ligature of the first twin's cord, tocolysis, continuous or periodic antibiotic therapy, corticosteroid therapy, cerclage (encircling cervical tissue with a ligature to prevent spontaneous abortion; this is usually done immediately after delivery of twin 1, although this has been controversial), and anticoagulation in selected cases.

Interestingly, Fayad et al. and others detected a trend toward better outcomes for twin 2 if twin 1 was delivered early in the pregnancy. At this time, future studies need to assess long-term physical development of twin infants delivered weeks and months apart. Parents' attachment to twins arriving home second is also important to consider; it is generally suggested that twins born at about the same time should go home together, even if this means delaying the release of one to accommodate the needs of the other.

\section{Research Summaries: Relationships, Chorions and Chromosomes}

\section{Twin Relationships: Communication and Longevity.}

It is now well known that MZ twins' social relationships are, on average, closer and more enduring than those of DZ twins and other pairs of relatives (Segal, 2000). Possible benefits of communication between twins and MZ-DZ twin differences in close contact and related behaviors were explored by Zaretsy (2003), using twins from the National Academy of ScienceNational Research Council (NASNRC) World War II Veteran Twins Registry. This registry includes information on mortality and zygosity for 11,832 MZ twins and 15,062 DZ twins, born between 1917 and 1927 . Mortality data were obtained from the Department of Veterans Affairs. Results from the present study were based on data gathered through November 1999. Surveys distributed and received from a subsample of twins requested information on the nature and frequency of inter-twin communication, exercise regimens, alcohol consumption and smoking behaviors. Marital status and related measures were also obtained.

A selected sampling of the intriguing findings from this study are summarized as follows: (1) Survival was longer for $M Z$ than DZ twins who lived to at least 35 years of age. Median survival time for $\mathrm{MZ}$ twins was 82 years $(81.5$ to 82.5$)$ and median survival time for DZ twins was 80.5 years $(79.9$ to 81.1). (2) Probability of survival was significantly greater for $\mathrm{MZ}$ twins than for DZ twins, for individuals age 50 and above. (3) Frequent inter-twin communication was associated with reduced mortality for $M Z$ twins, but not for DZ twins. This was true when communication was confined to pairs in contact with one another once per month or more, but not for twins who were in contact less frequently. Social relations with close friends and other relatives did not meaningfully affect the findings. (4) Smoking, exercise, living with both parents until age 15 and having a current marriage in 1983 were associated with longevity in twins of both zygosities. However, alcohol consumption, body mass index and previous marriages were not significantly related to survival. Interestingly, decreased smoking, increased exercise and having a current marriage were more beneficial to $\mathrm{MZ}$ than $\mathrm{DZ}$ twins. (5) Heritability of longevity in this study was calculated to be $20 \%$ to $30 \%$, similar to findings from other studies. Results from this work are, of course, applicable only to males. Additional research will be needed in order to know if the findings also extend to females. Further efforts are also needed to identify the behavioral and physical correlates of close communication relevant to enhanced longevity and health.

\section{Chorions: Dizygous Monochorionic Twins}

It is both unsettling and satisfying when scientific studies challenge prevailing wisdom. A "rule" in the biology of twinning has been that monochorionicity proves $\mathrm{MZ}$ twinning. However, a case report by Souter, Kapur, Nyholt, et al. (2003) shows that this may not always be the case - although the twins in questions were conceived via in vitro fertilization (IVF), rather than by natural means.

A 48-year-old woman underwent IVF using donor eggs. Three viable embryos were transferred to her uterus at the blastocyst stage. Ultrasonography at 12 weeks revealed one nonviable fetus and a pair of viable twin fetuses. A monochorionic, diamniotic placenta was identified; thus, the twins were presumed to be MZ. However, an ultrasound at 20 weeks indicated one male and one female fetus; and a healthy opposite-sex twin pair was delivered at 37 weeks. Blood samples taken from the twins at one week of age showed high levels of blood chimerism - clearly, in utero blood exchange had occurred between the twins, although it was the female who showed a preponderance of malederived lymphocytes. Understandably, zygosity studies based on blood-typing were consistent with $\mathrm{MZ}$ twins.

The mechanisms underlying monochorionicity in DZ twins remain speculative. The investigators reasoned that trophoblasts (outermost layer of the developing blastocyst) from the two embryos may have fused to yield two genetically separate non-chimeric inner cell masses within a single chimeric trophoblast "shell". Whether this did occur, and whether such a process 
might be limited to multiples conceived via artificial reproduction remains unknown.

Several important implications derive from this report. (1) Single chorions cannot be considered proof of MZ twinning. Some researchers may want to reassess zygosity in cases for which assignments as MZ have seemed questionable. (2) Blood chimerism may, in some cases, compromise the accuracy of zygosity diagnosis. The authors suggest that using DNA derived from buccal cells may circumvent this problem.

It should be pointed out that Souter et al.'s report is not the first time a single chorion has been associated with DZ twins. A paper by Bieber et al. (1981) described a case of polar body twinning in which the pair included a normal male twin and malformed female fetus (polar body twinning refers to twins resulting from the fertilization of a mature ovum and polar body, a small cell produced during maturation of the immature oocyte. Polar bodies are typically not fertilized). This paper was not cited in Souter et al.'s report, although they did not indicate that theirs was the first case of DZ twins with a single chorion. Unfortunately, newspaper coverage incorrectly made this claim (Duenwald, 2003).

\section{Chromosomes: $M Z$ Twins Discordant for Hemihypertrophy.}

Hemihypertrophy is a condition involving asymmetrical overgrowth of the cranium, face, limbs and/or trunk. This overgrowth is confined to one side of the body. It's incidence is $1 / 86,000$ live births, and a male: female ratio of 1:2 has been observed. Underlying causal factors are not yet definitive, but the condition has been linked to an area of the $11 \mathrm{p} 15$ locus, also associated with Beckwith-Wiedemann syndrome (BWS), a disorder involving asymmetrical overgrowth.

MZ twins discordant for medical disorders are always of interest. These natural co-twin control cases can potentially isolate factors triggering a condition in one co-twin, while suppressing it in the other. The present case, reported by West, Love, Stapleton, and Winship (2003), is exemplary. The twins in question were $\mathrm{MZ}$ females, of which the secondborn twin was affected. They were born following a normal pregnancy lasting 36 weeks. They showed favorable postnatal heath with the exception of twin 2's hemihypertrophy; she showed overgrowth of the right leg, arm and kidney. Monozygosity was established by DNA profiling. The twins had identical profiles, except for the suspected region, the 11 p15 STR, THO1 locus unbalanced amplification was noted in the affected twin. Further study of a nearby allelic pair showed imbalance for twin 2 at both loci; the maternal allele was marginally present. However, twin 1 showed amplification of both relevant maternal and paternal alleles. This result was indicative of uniparental disomy of the paternal allele at the $11 \mathrm{p} 15$ locus, in the affected twin. (Uniparental disomy is a condition in which two copies of one chromosome derived from a single parent, and no copies came from the other parent.)

The investigators noted that the genetic phenomenon seen in the present case has been described previously. Uniparental disomy is consistent with the theory that physical overgrowth of one side of the body maybe due to overexpression of the paternally derived growth factor or underexpression of the maternally derived growth factor. In addition, an association between BWS and MZ twinning has been reported, especially in female twins. Some researchers suspect that the altered gene expression may give rise to two distinct cell clones, hence one possible cause of $\mathrm{MZ}$ twinning.

\section{In the Real World Breaking News}

The New Yorker magazine reported an unusual twin story in its June, 2003, issue (Wilkinson, 2003). Identical twins, Robert and Steven Gessmann, from New Jersey, operate Breaking News Network (BNN), a service providing local news to CNN, New York City television stations and New York City newspapers. Their fascination with daily breaking news events can be traced to a childhood ritual. Their parents, fascinated by huge fires, would travel to the scenes of disasters to witness them first hand. They took their twin sons with them. The twins began listening for fires on their twoway radio - and if news of out of control flames came across the wires they would notify their parents, then the family would head out to take a look. The Gessmann twins turned this childhood pastime into an important and fulfilling job. They provide clients with pagers to send in news happening anywhere from Virginia to parts of Connecticut. Situated in their New Jersey office, they pay attention to what comes through their scanners. They say that an increase in voice tone indicates a newsworthy event. Steven Gessmann regards the twins' sensitivity to changes in tonal quality as an original skill. To my knowledge, no one has formally studied sources of influence on this specific behavior. Given that both twins have this ability, a genetic link is likely.

\section{School Days}

The question of whether to separate twins and triplets in school is a trying decision for many parents of multiple birth children. School administrators and educators often assign multiples to separate classrooms automatically, assuming that this helps foster individuality and identity. There is, however, virtually no research evidence to support this practice. Researchers currently favor treating each pair on a case-by-case basis, making this decision a cooperative venture among parents, school personnel and others.

In the fall of 2003, a New York mother, Hazel Rosario, was faced with a very unusual situation (Gershman, 2003). It was the first day of kindergarten and she learned that two of her triplet sons, Matthew and Messiah, were assigned to one elementary school and her third son, Marcus, was assigned to a different school three miles away. Preparing young multiples for school can be a novel complex process, involving separation from parents, home and sometimes each other. In this case, the separation was far more extreme and would leave Marcus wondering why he was separated from his brothers. Furthermore, Marcus has cerebral palsy. Mrs. Rosario wanted all three children in the same class (and the same type of class) called "kindergarten plus" this is a program mixing special education students with others. 
One school official explained the error by pointing out that Mrs. Rosario waited until quite late to register her children for the school year. However, he promised to try to rectify the situation. Hopefully, this incident will alert teachers and other educators to the importance of keeping twins and triplets together in the early years if parents feel this is in their best interests.

\section{Media}

In August, 2003 I traveled to New York City to participate in the filming of a special segment on reared apart twins for the CBS's news magazine Forty-Eight Hours. It was such a pleasure to spend 2 full days with four sets of twins I knew well from my days at the University of Minnesota, and to meet a fifth newly reunited set. At the end of the first day, we went out to

\section{References}

Benden, D., Miller, M., \& Hatoum, N. (200I). 39-day delay in delivery of twins. Journal of Reproductive Medicine, 46, I07I-1077.

Bieber, F. R., et al. (I98I). Genetic studies of an acardiac monster: Evidence of polar body twinning in man. Science, 213 , 775-777.

Carson, J. L. (1888). Twins born with an interval of forty-four days. British Medical Journal, I, 242

Duenwald, M. (I 5 July 2003). A first: Fraternal twins, one placenta. New York Times, p. F-5.

Fayad, S., Bongain, A., Holhfeld, P., et al. (2003). Delayed delivery of second twin: A multicentre study of 35 cases. dinner at a lively Italian restaurant. The five sets of twins attracted an enormous amount of attention, especially from diners lined up near the entrance waiting for their reservations to be honored. But the most excited guests were a pair of blond identical twin women who had been brought to New York to appear in a segment of a show on a different television network. One of these twins had adopted a male-female set of her own.

I could not help but realize - yet again — how fascinating identical twins are to the general public. Their matched physical and behavioral traits keep everyone interested. Even while we are starting to understand more about the underlying genetic mechanisms giving rise to identical twins' similar development, a scientific perspective does not seem to decrease

European Journal of Obstetrics and Gynecology and Reproductive Biology, 109, 16-20.

Gershman, J. (9 September 2003). Education Dept. splits triplets. New York Sun, p. 2.

New York Times (12 November 1999). Boy is born 5 months after his twin died.

Odukogbe, A. A., Adesina, O. A., Barbainsa, I. A., Onifade, R.A., \& Adewole, I. F. (2002). Sixty-one day twin to twin birth interval in a low technology setting. African Journal of Medical Science, 3I, 275-276.

Segal, N. L. (1999). Entwined lives: Twins and what they tell us about human behavior. New York: Plume.

Souter, V. L., Kapur, R. P., Nyholt, D. R., et al. (2003).A report of dizygous monochori- their widespread wonder. I also realized that if I had arrived at the restaurant with four sets of fraternal twins (whether reared apart or reared together) no one would have noticed. And had viewers known these were twins, they would not have shown the same high level of interest. I know I am a fraternal twin and whenever I go out with my twin sister, which is rare these days given that we live on opposite coasts, no one knows but us.

\section{Author Note}

Definitions of some medical terms come from Taber's cyclopedic medical dictionary (3rd ed.; 1997). Philadelphia: F. A. Davis; L. B. Jorde, J. C. Carey, M. J. Bamshad, \& R. L. White (Eds.), Medical genetics. St Louis, MO: Mosby.

onic twins. The New England Journal of Medicine, 349, I54-I 58.

West, P. M. H., Love, D. R., Stapleton, P. M., \& Winship, I. M. (2003). Paternal uniparental disomy in monozygotic twins discordant for hemihypertrophy. Journal of Medical Genetics, 40, 223-226.

Wilkinson, A. (16 \& 23 June 2003). This just in dept: Calling all cars. The New Yorker Magazine, p. 74.

Zaretsky, M. D. (2003). Communication between identical twins: Health behavior and social factors are associated with longevity that is greater among identical than fraternal U.S. World War II veteran twins. Journal of Gerontology (Medical Science), 58A, 566-572. 